\title{
Evidence for the Role of Platelet-activating Factor in Immune Complex Vasculitis in the Rat
}

Jeffrey S. Warren, David M. Mandel, Kent J. Johnson, and Peter A. Ward

Department of Pathology, The University of Michigan Medical School, Ann Arbor, Michigan 48109

\begin{abstract}
These studies were designed to determine the role of plateletactivating factor (PAF) in the pathogenesis of immune complex (IgG) induced dermal vasculitis in the rat. In vitro, very low (pM and $\mathrm{nM}$ ) concentrations of PAF "primed" rat neutrophils for enhanced $O \dot{2}$ responses to IgG immune complexes while higher concentrations were directly stimulatory. The PAF receptor antagonist, $L-652,731$, blocked responses $\left(\mathrm{O}^{\dot{2}}\right.$ production and enzyme release) of rat neutrophils stimulated with PAF but did not block responses triggered by immune complexes, formyl chemotactic peptide or opsonized zymosan particles. When L-652,731 was added to the antibody employed in the reversed passive Arthus reaction, the injury resulting from immune complex-induced vasculitis was signifcantly attenuated. In order to determine if in vivo protection provided by $\mathbf{L}-652,731$ was related to neutrophils, we developed a new model in which rats are systemically depleted of neutrophils by cyclophosphamide and then locally reconstituted with intact neutrophils in a manner that allows restoration of immune complex-induced vascular injury. With this model, we demonstrated that the effects of neutrophil reconstitution are substantially diminished if the cells are pretreated with $L-652,731$ and then washed. By priming neutrophils with substimulatory concentrations of PAF, we have also provided in vivo evidence that neutrophil priming can increase the magnitude of vascular injury. These data provide evidence that vascular injury associated with immune complex dermal vasculitis is related to availability of PAF receptors on neutrophils, suggesting a mechanism through which PAF may function as a mediator in the pathogenesis of immune complex vasculitis.
\end{abstract}

\section{Introduction}

Cellular and humoral responses triggered by immune complexes are important in the pathogenesis of many inflammatory diseases. Formation of complement-fixing immune complexes in tissue can lead to a localized influx of neutrophils, which in turn release a diverse array of soluble mediators responsible for tissue damage (1-4). Considerable attention has been directed toward the proinflammatory roles of lysosomal granule constituents (e.g., proteases), oxidants (e.g., superox-

Address reprint requests to Dr. Warren, Department of Pathology, Box 0602, The University of Michigan Medical School, 1301 Catherine St., Ann Arbor, MI 48109.

Received for publication 2 February 1988 and in revised form 8 August 1988 .

J. Clin. Invest.

(c) The American Society for Clinical Investigation, Inc.

$0021-9738 / 89 / 02 / 0669 / 10 \quad \$ 2.00$

Volume 83, February 1989, 669-678 ide anion and its derivatives), and products of arachidonic acid. Platelet-activating factor (PAF, 1-O-alkyl-2-acetyl-snglycero-3-phosphocholine $)^{1}$ is elaborated by platelets, hepatocytes, endothelial cells, and by various inflammatory cells including monocytes, macrophages, neutrophils, and basophils (5). Recently, mediator functions of PAF have been examined in the context of tissue-damaging acute inflammatory processes (6-12). Concomitant in vitro studies have shown that, depending upon concentration, PAF can prime or directly activate granulocytes (13-20). Vercellotti et al. (20) have recently shown that PAF priming of neutrophils leads to enhancement of superoxide generation, elastase release, aggregation, adhesive glycoprotein expression and lysis or detachment of endothelial cells.

In several animal species there is in vivo and in vitro evidence that PAF participates in immune complex-mediated processes. After addition of sensitizing antigen, PAF is produced by isolated IgE-sensitized mast cells (21) and basophils (22). IgG aggregates or preformed immune complexes stimulate PAF production by isolated perfused rat livers (23), peritoneal macrophages (24), and isolated peripheral blood neutrophils and monocytes (25-28). PAF appears in the blood after induction of serum sickness (29), systemic anaphylaxis (30), and acute lung injury (31) in rabbits as well as after infusion of antigen into IgE-sensitized rabbits (32). Intravenous infusion of immune complexes or IgG aggregates into rabbits and mice results in the appearance of PAF in the blood and liver, respectively $(26,33)$. Increased vascular permeability, systemic hypotension, intravascular lysosomal hydrolase secretion and neutropenia can be elicited by infusion of preformed immune complexes or IgG aggregates $(33,34)$. These physiologic responses to immune complexes can be mimicked by infusion of PAF (26, 35-38). Additional support that responses to immune complex infusions may be mediated by PAF has been provided by studies in which both immune complex-induced PAF production and neutropenia are blocked by 6-methylprednisolone (26) and $\mathrm{PGI}_{2}(25,35)$. PAF production and vascular permeability resulting from infusion of aggregated IgG into mice can be prevented by mononuclear phagocyte depletion suggesting that some immune complex-induced responses are mediated by PAF (33).

There is convincing in vivo and in vitro evidence that PAF can directly provoke rapid neutrophil-independent increases in microvascular permeability. Intradermal injection of PAF into rabbits results in a rapid, localized increase in vascular permeability independent of neutrophil, mast cell or platelet activation (6-11). Hellewell and Williams (12) have recently provided evidence that endogenous PAF production may contribute to changes in endothelial cells in postcapillary venules $(39,40)$. In vitro studies with cultured human endothelial cells

1. Abbreviations used in this paper: PAF, platelet activating factor. 
have shown that PAF stimulates $\mathrm{Ca}^{2+}$ influx-efflux $(41,42)$ and associated cytoskeletal alterations that are associated with changes in cell shape and monolayer permeability to iodinated albumin (43).

The present study addresses a potential autocrine-paracrine role for PAF in neutrophil-dependent immune complexinduced vascular injury. We present evidence that PAF, in addition to its putative role in neutrophil-independent early phase increases in vascular permeability, also contributes to immune complex induced vascular damage through interaction with PAF receptors on neutrophils.

\section{Methods}

Animals. Male Long-Evans specific pathogen-free rats (300-400 g; Charles River Breeding Laboratories, Inc., Wilmington, MA) were used for all studies. Intraperitoneal injections of ketamine (2.5-5.0 $\mathrm{mg} / 100 \mathrm{~g}$ body $\mathrm{wt})$ and sodium pentobarbital $(5 \mathrm{mg} / 100 \mathrm{~g}$ body $\mathrm{wt})$ were given for sedation and anesthesia.

Materials. L-652,731 (trans-2,5-bis; 3,4,5-trimethoxyphenyl tetrahydrofuran) and its cis-isomer, L-652,763 were from Dr. John C. Chabala, Merck, Sharp and Dohme, Rahway, NJ. Stock solutions of $\mathrm{L}-652,731$ and $\mathrm{L}-652,763(0.4 \mathrm{mg} / \mathrm{ml}$ sterile saline $)$ were prepared daily in $1.0 \%$ dimethylsulfoxide (DMSO). Final concentrations of DMSO never exceeded $0.1 \%$ in any in vitro or in vivo experiments. Fluoresceinated $\mathrm{F}\left(\mathrm{ab}^{\prime}\right)_{2}$ fragments (anti-BSA and anti-rabbit IgG) were purchased from Cooper Biomedical, Malvern, PA. Zymosan, FMLP, PAF, 2-deoxyribose, hypoxanthine, xanthine oxidase, thiobarbituric acid, and BSA (Cohn fraction V, essentially fatty acid free) were from Sigma Chemical Co., St. Louis, MO. 1-O- $\left[{ }^{3} \mathrm{H}\right]$ hexadecyl-2acetylglycero-3-phosphocholine $(59 \mathrm{Ci} / \mathrm{mmol})\left({ }^{3} \mathrm{H}-\mathrm{PAF}\right)$ was purchased from New England Nuclear (Boston, MA). PAF activity was ascertained by measuring platelet release of serotonin (44). Rat platelets were isolated as described by Henson (45). Platelet-rich plasma was removed, pooled, and incubated at $37^{\circ} \mathrm{C}$ with $1 \mu \mathrm{Ci} / \mathrm{ml}\left[{ }^{3} \mathrm{H}\right]$ serotonin binoxalate (New England Nuclear) for $15 \mathrm{~min}$. The platelets were sedimented at $2,500 \mathrm{~g}$ for $15 \mathrm{~min}$ and washed first in Tyrode's-gel without $\mathrm{Ca}^{2+}$ and with EGTA and then in Tyrode's-gel without $\mathrm{Ca}^{2+}$. $2.5 \times 10^{8}\left[{ }^{3} \mathrm{H}\right]$ serotonin-labeled platelets were finally incubated $\left(37^{\circ} \mathrm{C}\right.$, $15 \mathrm{~min}$ ) in duplicate with stimuli in a final volume of $0.4 \mathrm{ml}$ Tyrode'sgel with $\mathrm{Ca}^{2+}$. The reaction was stopped by centrifuging at $12,000 \mathrm{~g}$ in a microfuge-12 (Beckman Instruments, Inc., Fullerton, CA) for $30 \mathrm{~s}$. Serotonin release was measured by counting an aliquot of the supernatant fluid in a liquid scintillation counter. Serotonin release was expressed as a percentage of the total where total was determined after Triton X-100 lysis of $\left[{ }^{3} \mathrm{H}\right]$ serotonin-labeled platelets. Incubation of platelets with increasing concentrations of $\operatorname{PAF}\left(10^{-7}-10^{-5} \mathrm{M}\right)$ resulted in dose-dependent serotonin release ranging from 6.0 to $95.9 \%$. Stimulation of platelets with thrombin ( $1 \mathrm{U}$; Sigma) resulted in $71.0 \%$ serotonin release. Assay of platelet supernatants for lactate dehydrogenase (LDH) (46) revealed no evidence of platelet lysis by the commercial PAF preparation.

Buffers. Tyrode's-gel without $\mathrm{Ca}^{2+}$, Tyrode's-gel without $\mathrm{Ca}^{2+}$ with EDTA, Tyrode's-gel with $\mathrm{Ca}^{2+}$, Tyrode's-BSA without $\mathrm{Ca}^{2+}$ and Tyrode's-BSA with $\mathrm{Ca}^{2+}$ were prepared as described by Lynch et al. (44).

Peripheral blood neutrophils. Heparinized caval blood was collected from Long-Evans rats, pooled within the group, and the neutrophils isolated by centrifugation over a Histopague- 1077 gradient after sedimentation of red blood cells with hydroxyethyl starch (6\% Volex; McGaw Laboratories, Glendale, CA) (44). Residual erythrocytes were removed by hypotonic lysis. The purified neutrophils were suspended in Tyrode's-BSA with or without $\mathrm{Ca}^{2+}, \mathrm{Mg}^{2+}$, and glucose as indicated.

Immune complex preparation. Immune complexes were prepared with the use of hyperimmune rabbit IgG rich in antibody to BSA. As previously described, the concentration of antibody was determined by quantitative precipitin reactions (47). Complexes were prepared with a constant antigen/antibody ratio (wt/wt) of 1:5.
Measurements of $\mathrm{O}_{2}^{-}$production and beta-glucuronidase release. Superoxide generation by neutrophils was measured by the superoxide dismutase-inhibitable reduction of ferricytochrome $c$ according to $\mathrm{Ba}$ bior et al. (48) and recently detailed (49). Tyrode's-BSA with $\mathrm{Ca}^{2+}$ was used in place of HBSS.

The release of lysosomal enzyme beta-glucuronidase by neutrophils was measured as recently detailed (49). Again, Tyrodes-BSA with $\mathrm{Ca}^{2+}$ was substituted for HBSS during neutrophil incubations.

$P A F$-receptor binding studies. The binding of ${ }^{3} \mathrm{H}-\mathrm{PAF}$ to isolated peripheral blood rat neutrophils and the inhibition of ${ }^{3} \mathrm{H}-\mathrm{PAF}$ binding to neutrophils by the PAF antagonist, L-652,731, were carried out by adapting methods described by Hwang et al. (50). Neutrophils (2 $\times 10^{6}$ ) were added to final $1 \mathrm{ml}$ solutions of $\mathrm{Ca}^{2+}, \mathrm{Mg}^{2+}$, and glucosefree Tyrode's-BSA buffer ( $\mathrm{pH}$ 7.2) containing $2.2 \mathrm{nM}\left[{ }^{3} \mathrm{H}\right] \mathrm{PAF}$ and known amounts of $\mathrm{L}-652,731$. After $30 \mathrm{~min}$ incubation at $4^{\circ} \mathrm{C}$, the mixtures were filtered through GF/C glass fibers under vacuum. Percent inhibition of ${ }^{3} \mathrm{H}-\mathrm{PAF}$ binding by L-652,731 was calculated as \% inhibition $=$ total binding - total binding with antagonist/specific binding $\times 100 \%$, where total binding was defined as described by Hwang et al. (50). Nonspecific binding, measured in the presence of an excess of PAF $(10 \mu \mathrm{M})$ cannot be displaced with further increases in PAF concentration or with high concentrations of L-652,731 (100 $\mu \mathrm{M})$. Specific binding is the calculated difference between total and nonspecific binding.

Animal models of dermal vasculitis. Reversed dermal Arthus reactions were induced in rats by intradermal injection of $50 \mu \mathrm{l}$ antibody (10 or $20 \mu \mathrm{g}$, directed against BSA) in the presence or absence of $\mathrm{L}-652,731$ or $\mathrm{L}-652,763$. The antibody was prepared from hyperimmune rabbit serum by isolating the IgG fraction by means of saturated ammonium sulfate $(50 \%)$ precipitation and diethylaminoethyl-cellulose ion exchange chromatography as previously described $(51,52)$. Immediately after intradermal injection of antibody, the rats received intravenous injections of BSA (10 mg in $1.0 \mathrm{ml}$ saline), which also contained an aliquot $(800,000 \mathrm{cpm})$ of radioactive indicator $\left({ }^{125} \mathrm{I}\right.$-labeled nonspecific rabbit $\mathrm{IgG}$ ) for quantitation of dermal vascular injury. At specified time points, the rats were killed and tissue injury was quantitated by determination of the permeability index. As described previously, the permeability index in this model is the amount of radioactivity present within standard size full-thickness skin sites, compared with the radioactivity within $1.0 \mathrm{ml}$ of caval blood (53).

To examine the role of PAF-receptors on neutrophils in immune complex vasculitis, rats were depleted of neutrophils $\left(<200 / \mathrm{mm}^{3}\right)$ with cyclophosphamide $(75-100 \mathrm{mg} / \mathrm{kg}$ i.p., $4 \mathrm{~d}$ before experiment) and dermal Arthus reactions were reconstituted by injecting antibody intradermally together with neutrophils $\left(10^{6}\right)$ that had been pretreated with $50 \mu \mathrm{M} \mathrm{L}-652,731$, L-652,763, or buffer and then washed. Vascular injury was quantitated after $30 \mathrm{~min}, 1$ or $2 \mathrm{~h}$ as detailed above.

Morphologic analysis of dermal vasculitis. Transmission electron micrographs were prepared from biopsies fixed in $4 \%$ glutaraldehyde, washed in $0.1 \mathrm{M}$ cacodylate buffer ( $\mathrm{pH} 7.3$ ), and embedded in plastic. $1-\mu \mathrm{m}$-thick sections were stained with toluidine blue and processed for transmission electron microscopy by using a Philips 401 transmission electron microscope (Philips Electronic Instruments, Mahwah, NJ).

Immunofluorescence studies were performed on cryostat sections of reversed dermal Arthus and reconstituted dermal vasculitis skin biopsies. Frozen sections were fixed in acetone $(10 \mathrm{~min})$, twice washed with PBS (5 min), and incubated (40 $\mathrm{min}$; room temperature) with $1: 50,1: 100$, and $1: 200$ dilutions of fluoresceinated rabbit $F\left(a b^{\prime}\right)_{2}$ directed against bovine serum albumin, fluoresceinated goat anti-rabbit IgG (heavy and light chain specific) $F\left(a^{\prime}\right)_{2}$ fragments, or saline. The sections were then washed with PBS (10 $\mathrm{min} \times 3)$ and coverslipped with $0.1 \%$ p-phenylenediamine in glycerol. Sections were examined and photographed using a Zeiss Photomic III epifluorescent microscope.

Hydroxyl radical generation and measurement. Cell-free generation of hydroxyl radical was achieved by a hypoxanthine-xanthine oxidase system in the presence of added iron salt (54). Hydroxyl radicals were detected by generation of thiobarbituric acid reactive chro- 
mogens resulting from deoxyribose degradation (55). Briefly, reaction mixtures containing $200 \mu \mathrm{l}$ 2-deoxy-D-ribose $(5 \mathrm{mM}), 200 \mu \mathrm{l}$ buffer, pH $7.4(0.024 \mathrm{M}$ phosphate, $0.15 \mathrm{M} \mathrm{NaCl}), 200 \mu$ l hypoxanthine (2 $\mathrm{mM}), 50 \mu \mathrm{FeCl}{ }_{3}(1 \mathrm{mM})$ and $20 \mu \mathrm{l}$ xanthine oxidase $(51.7 \mathrm{U} / \mathrm{ml})$ were incubated at $37^{\circ} \mathrm{C}$ for $30 \mathrm{~min}$. The buffer contained mannitol (10 $\mathrm{mM}), \mathrm{L}-652,731$ or $0.1 \%$ DMSO as indicated. After incubation, $0.5 \mathrm{ml}$ of $1 \%(\mathrm{wt} / \mathrm{vol}$ ) thiobarbituric acid (dissolved in $0.05 \mathrm{M} \mathrm{NaOH}$ ) and 0.5 $\mathrm{ml} 2.8 \%$ (wt/vol) TCA was added. The mixtures were heated at $100^{\circ} \mathrm{C}$ for $10 \mathrm{~min}$, cooled, and absorbances measured at $532 \mathrm{~nm}$.

\section{Results}

Specific blockade of PAF-triggered rat neutrophil activation. Addition of increasing concentrations of PAF to rat peripheral blood neutrophils resulted in dose-dependent increases in $\mathrm{O}_{2}^{-}$ generation (Fig. 1). However, when PAF over the same range of concentrations was added to neutrophils in the presence of the PAF receptor antagonist, L-652,731 (50 $\mu \mathrm{M})$, there was complete blockade of $\mathrm{O}_{2}^{-}$production. In the presence of $5 \mu \mathrm{M}$ L-652,731, the effect of the antagonist could be overridden by the highest concentration of PAF $\left(10^{-5} \mathrm{M}\right)$.

The data shown in Fig. 2 demonstrate the specificity of L-652,731 with respect to PAF-triggered $\mathrm{O}_{2}^{-}$responses and enzyme release. The lack of effect of $\mathrm{L}-652,731$ on $\mathrm{O}_{2}^{-}$generation triggered by immune complexes, FMLP or opsonized zymosan is consistent with the specificity of L-652,731 for PAF receptors and indicates that as much as $50 \mu \mathrm{M}$ L-652,731 does not interfere with the neutrophil oxidative burst or measurement of $\mathrm{O}_{2}^{+}$per se. L-652,731 specifically blocked PAF-induced $\beta$-glucuronidase secretion, but not enzyme secretion induced by the other agonists. Under identical conditions, PAFtriggered activation of neutrophils was not blocked by L-652,763 $(50 \mu \mathrm{M})$, the cis-isomer of L-652,731.

In vitro priming of rat neutrophils with $P A F$. To investigate the ability of PAF to "prime" neutrophils for superoxide responses, cells were incubated in the presence or absence of PAF at concentrations ranging from $10^{-11}$ to $10^{-7} \mathrm{M}$. Neutrophils were incubated for $5 \mathrm{~min}$ at $37^{\circ} \mathrm{C}$ with buffer alone or

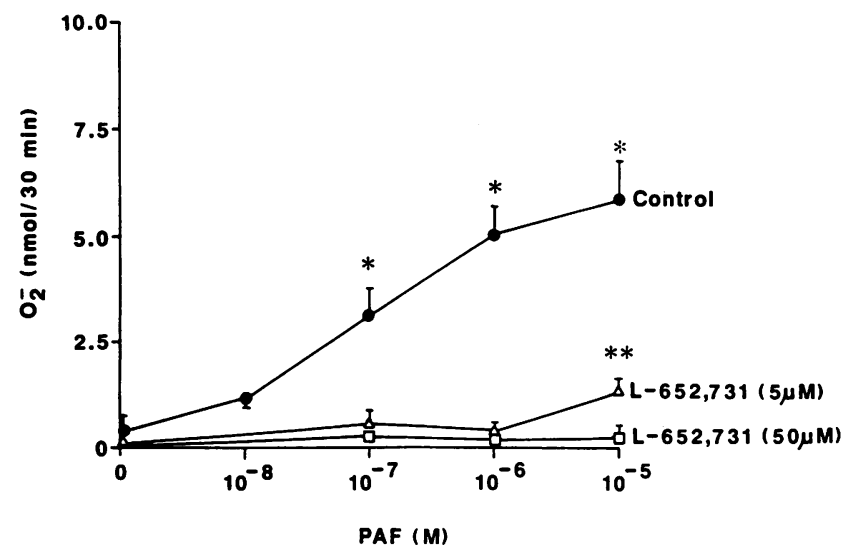

Figure 1. Effect of L-652,731 (5 and $50 \mu \mathrm{M})$ on rat neutrophil $\mathrm{O}_{2}^{-}$ production triggered by increasing concentrations of PAF. Rat peripheral blood neutrophils $\left(2 \times 10^{6} / \mathrm{ml}\right)$ suspended in Tyrode's-BSA with $\mathrm{Ca}^{2+}$ (in the presence or absence of $\mathrm{L}-652,731$ ) were incubated $\left(37^{\circ} \mathrm{C}, 30 \mathrm{~min}\right)$ with increasing concentrations of PAF. $\mathrm{O}_{2}^{-}$production was determined by SOD-inhibitable reduction of ferricytochrome $c$ as previously described (48). Data expressed are means \pm SEM of four experiments in which duplicate samples were assayed. Data were analyzed by analysis of variance with significance assigned for $P<0.05$. * and ** Significant differences versus $\mathrm{O}_{2}^{-}$ values measured in the absence of PAF.
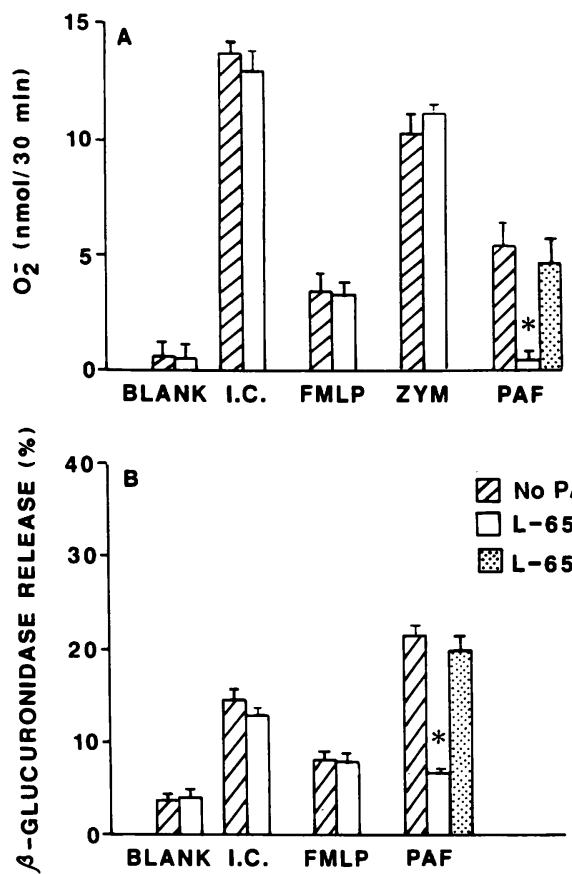

Figure 2. Effects of L-652,731 $(50 \mu \mathrm{M})$ and $\mathrm{L}-652,763(50 \mu \mathrm{M})$ on rat neutrophil $\mathrm{O}_{2}^{-}$production and $\beta$-glucuronidase secretion induced by IgG immune complexes ( $10 \mu \mathrm{g}$ antibody/ml), FMLP $\left(10^{-7} \mathrm{M}\right)$, opsonized zymosan $(1 \mathrm{mg} / \mathrm{ml})$ and $\operatorname{PAF}\left(10^{-5} \mathrm{M}\right)$. Incubation conditions for $\mathrm{O}_{2}^{\dot{2}}$ determination and $\beta$-glucuronidase secretion assays were the same as described for Fig. 1. For enzyme secretion, releasates from blood neutrophils $\left(3 \times 10^{6}\right)$ were assayed as described previously (46). Percent enzyme release was relative to enzyme activity present in Triton X-100 neutrophil lysates. Data expressed are means \pm SEM of five experiments in which duplicate $\left(\mathrm{O}_{2}^{\dot{*}}\right)$ or triplicate (enzyme release) samples were assayed. The effect of $\mathrm{L}-652,763$ $(50 \mu \mathrm{M})$ on PAF-triggered responses was determined in two experiments. A two-tailed Student's $t$ test was used to analyze control (国) versus L-652,731 (ם), or L-652,763-treated () groups. * A significant difference $(P<0.05)$ between control and L-652,731-treated groups.

with $50 \mu \mathrm{M}$ L-652,731 and then washed. PAF or immune complexes were then added as indicated and $\mathrm{O}_{2}^{-}$production measured. As shown in Fig. 3, neutrophils preincubated only in buffer (without PAF) produced $3.8 \mathrm{nmol} \mathrm{O}_{2}^{-}$following addition of immune complexes. Negative control cells generated $0.4 \pm 0.3 \mathrm{nmol} \mathrm{O}_{2}^{-}$. Neutrophils that had been incubated in buffer alone and then exposed to increasing concentrations of PAF exhibited $\mathrm{O}_{2}^{-}$responses at concentrations of PAF of $10^{-8}$ $M$ and greater. Neutrophils exposed to very low concentrations $\left(10^{-11}\right.$ to $\left.10^{-9} \mathrm{M}\right)$ of PAF produced markedly increased amounts of $\mathrm{O}_{2}^{-}$following incubation with immune complexes. This "priming" effect was completely abolished when the neutrophils were preincubated with PAF in the presence of the PAF-receptor antagonist, L-652,731. These data suggest that PAF, at very low concentrations, can prime neutrophils resulting in an exaggerated $\mathrm{O}_{2}^{-}$response upon exposure to a second stimulus such as immune complexes. The ability to block this PAF-mediated effect with L-652,731 suggests that initiation of the priming phenomenon is linked to engagement of PAF receptors.

Blockade of neutrophil PAF receptors with $L-652,731$. The percent inhibition by L-652,731 of $\left[{ }^{3} \mathrm{H}\right] \mathrm{PAF}$ binding to PAFreceptor sites on peripheral blood rat neutrophils is shown in Fig. 4. L-652,731 inhibited $\left[{ }^{3} \mathrm{H}\right] \mathrm{PAF}(2.2 \mathrm{nM})$ receptor binding 


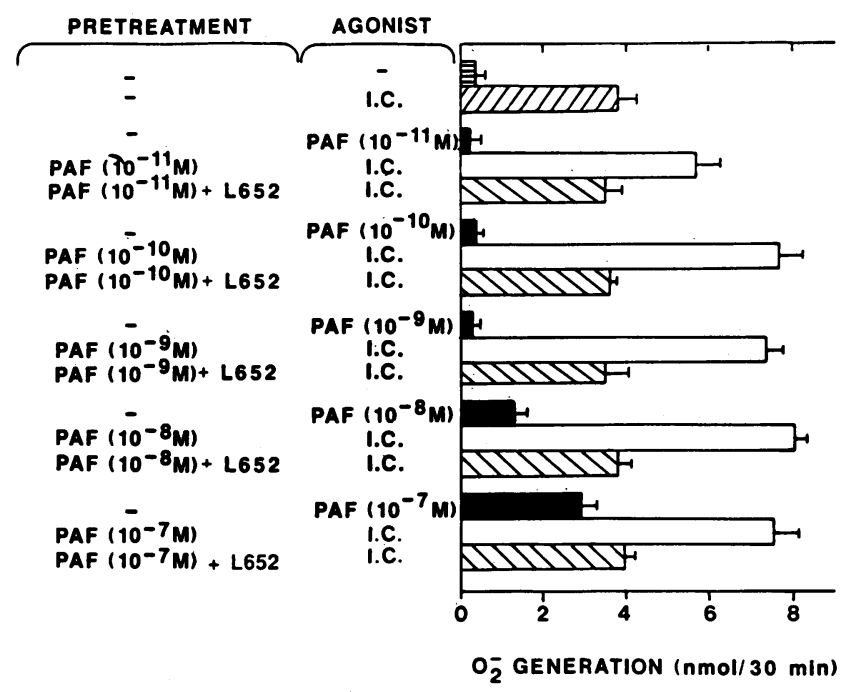

Figure 3. Effect on subsequent $\mathrm{O}_{2}^{-}$production of priming rat neutrophils with substimulatory (picomolar to nanomolar) concentrations of PAF. Neutrophils $\left(2 \times 10^{6} / \mathrm{ml}\right)$ were incubated $\left(37^{\circ} \mathrm{C}, 5 \mathrm{~min}\right)$ with increasing concentrations $\left(10^{-11}-10^{-7} \mathrm{M}\right)$ of PAF in the presence or absence of L-652,731 $(50 \mu \mathrm{M})$. After treatment, the cells were washed with Tyrodes-BSA with $\mathrm{Ca}^{2+}$, IgG immune complexes $(10 \mu \mathrm{g}$ antibody $/ \mathrm{ml}$ ) or PAF added, and $\mathrm{O}_{2}^{-}$generation measured. Data expressed are means \pm SEM of four separate experiments in which duplicate samples were assayed.

with an $\mathrm{ED}_{50}$ value of $2.4 \times 10^{-7} \mathrm{M}$, where $\mathrm{ED}_{50}$ represents the concentration of antagonist to block $50 \%\left[{ }^{3} \mathrm{H}\right] \mathrm{PAF}$-specific receptor binding. L-652,731-treated cells were analyzed in vitro to determine whether neutrophil functions and specific PAFreceptor blockade were preserved following this intervention. Incubation of neutrophils with L-652,731 followed by washing resulted in complete blockade of the PAF-triggered $\mathrm{O}_{2}^{-}$response and an $84 \%$ suppression of $\beta$-glucuronidase secretion (data not shown). As in the analyses of antagonist specificity for PAF-triggered neutrophil functions (Fig. 2), the receptorblocking effect of L-652,731 could be overridden with high concentrations of PAF $\left(10^{-5} \mathrm{M}\right)$ (data not shown). Exposure of

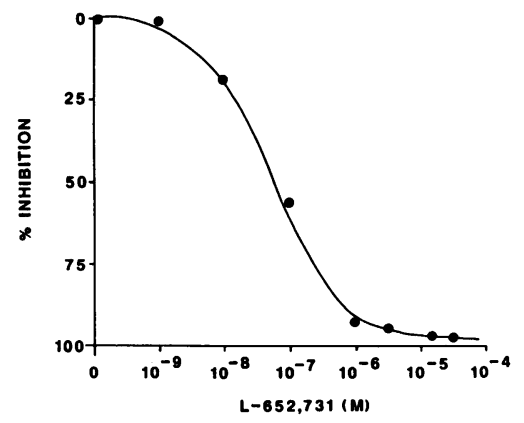

Figure 4. Inhibition curve of $\left[{ }^{3} \mathrm{H}\right] \mathrm{PAF}$ binding to the PAF-receptor on peripheral blood rat neutrophils by L-652,731. Neutrophils $\left(2 \times 10^{6} / \mathrm{ml}\right)$ were suspended in $\mathrm{Ca}^{2+}, \mathrm{Mg}^{2+}$, and glucose-free $\mathrm{Ty}$ rode's-BSA ( $\mathrm{pH} 7.2$ ) containing $2.2 \mathrm{nM}\left[{ }^{3} \mathrm{H}\right]-$ PAF and known amounts of $\mathrm{L}-652,731$.

After $30 \mathrm{~min}$ incubation at $4^{\circ} \mathrm{C}$, the mixtures were either filtered through $\mathrm{GF} / \mathrm{C}$ glass fiber filters under vacuum or assayed $\left(\mathrm{O}_{2}^{-}\right.$production and $\beta$-glucuronidase release) to assess maintenance of PAFreceptor blockade. The percent inhibition of $\left[{ }^{3} \mathrm{H}\right] \mathrm{PAF}$ binding by L-652,731 was calculated as described in Methods. Each point of inhibition represents the average of three experiments with duplicates or triplicates performed in each experiment. $\mathrm{ED}_{50}$ represents the concentration of L-652,731 required to displace $50 \%$ of the specific $\left[{ }^{3} \mathrm{H}\right]-$ PAF-receptor binding. cells to L-652,731 $(50 \mu \mathrm{M})$ appeared not to have a generalized suppressive effect on neutrophil functional responses since stimulation of antagonist treated cells with IgG immune complexes resulted in $\mathrm{O}_{2}^{+}$production and $\beta$-glucuronidase secretion equivalent to that produced by untreated cells.

In vivo evidence for $P A F$ in immune complex vasculitis. Intradermal injection of L-652,731 with antibody resulted in dose-dependent suppression of vascular injury (as measured by permeability change) induced by reversed passive Arthus reactions (Fig. 5). Parallel dose-response curves were observed for skin sites injected with $10-$ or 20- $\mu$ g antibody. At both antibody concentrations, vascular injury could be suppressed by as much as $45 \%$ in sites injected with $5 \times 10^{-8} \mathrm{~mol}$ L-652,731. Intradermal injection of equivalent concentrations of cis-isomer (L-652,763) with antibody resulted in no suppression of vascular injury. These data suggest that PAF plays a significant role in the pathogenesis of immune complex vasculitis.

Characterization of the "reconstituted" dermal vasculitis model. To develop a vasculitis model in which the role of PAF receptors on neutrophils could be examined, rats were depleted of granulocytes with cyclophosphamide and Arthus-like reactions were reconstituted by injection antibody intradermally together with aliquots of isolated peripheral blood neutrophils. Development of vascular injury, as defined by increased permeability, occurred in a dose-dependent manner similar in pattern to the classic reversed passive Arthus reaction (Fig. 6). At equivalent antibody doses, the absolute degree of vascular damage achieved in reconstituted sites ranged from 35 to $43 \%$ of that observed in reversed passive Arthus sites. In contrast to the reversed passive Arthus reaction, in which there is a time-dependent increase in perivascular neutrophil accumulation at sites of immune complex deposition, reconstituted vasculitis sites exhibited relatively uniform histologic appearances at $0.5,1$, and $2 \mathrm{~h}$ (Fig. 7). In the latter model, reconstituted neutrophils were distributed throughout the dermis and were less intimately associated with blood vessel walls

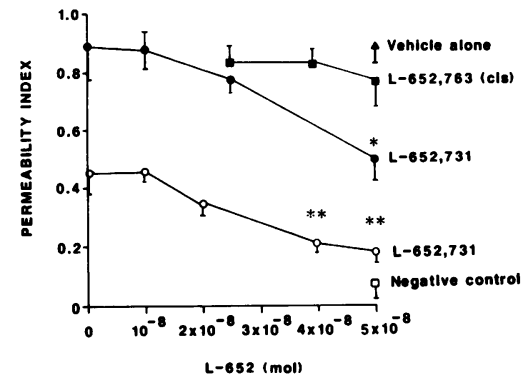

Figure 5. Effect of L-652,731 and L-652,763 on development of the reversed passive Arthus reaction. Skin sites were injected with IgG anti-BSA (10 $\mu \mathrm{g}$ antibody $[-\mathrm{O}-]$ or $20 \mu \mathrm{g}$ antibody $[-\bullet-])$ in the presence of increasing concentrations of

L-652,731 or L-652,763. Rats were sacrificed $2 \mathrm{~h}$ after induction of the reversed passive Arthus reaction and permeability indices were expressed as the ratio of ${ }^{125}$ I-nonspecific IgG counts per minute per skin site to counts per minute in $1 \mathrm{ml}$ of caval blood $(51,52)$. Vehicle alone $(\triangle)$ consists of $1.0 \%$ DMSO in $40^{\circ} \mathrm{C}$ saline as described previously. Negative control rats $(\square)$ received intradermal injections of antibody $(20 \mu \mathrm{g})$ and intravenous infusions saline containing ${ }^{125} \mathrm{I}-$ nonspecific IgG but no BSA. The data expressed are means \pm SEM of five separate experiments in which two to five replicate sites were employed for each variable. Data were analyzed by analysis of variance with significance assigned for $P<0.05$. and ** Significant differences in permeability indices from control sites injected with antibody but no L-652,731. 


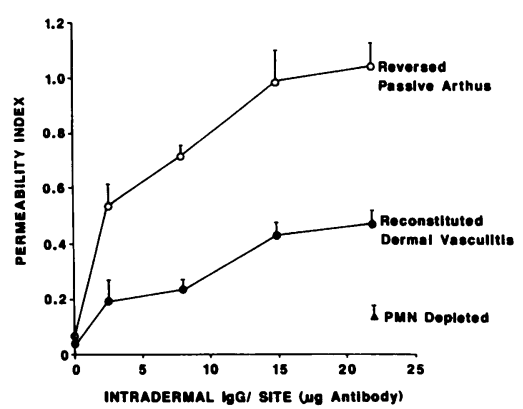

Figure 6. Comparison of permeability characteristics of the reconstituted dermal vasculitis model and the reversed passive Arthus reaction. Dermal vasculitis was reconstituted $(-\bullet-)$ by injecting IgG antiBSA with peripheral blood neutrophils $\left(10^{6}\right)$ into the dermis of neu-

trophil-depleted rats. Antigen (BSA, $10 \mathrm{mg}$ ) was injected intravenously, rats were sacrificed after $2 \mathrm{~h}$, and permeability indices determined as described previously. Some skin sites received only antibody $(\Lambda)$ or only neutrophils ( $0 \mu \mathrm{g}$ antibody). The data expressed represent means \pm SEM of three experiments in which three to four replicate sites were employed for each variable. Reversed passive Arthus reactions were induced using aliquots of the same antibody preparations and the reactions were terminated at $2 \mathrm{~h}$.

than in classic reversed passive Arthus reactions. The difference in neutrophil distribution in the reconstituted vasculitis model is perhaps best illustrated by the lack of neutrophils either within the vascular lumens or in the process of emigration through vessel walls. In both models, electron dense immune complex deposits were present within the neutrophils (Fig. 7). Immunofluorescence staining verified the presence of both antibody (rabbit IgG) and antigen (BSA) in association with the neutrophils (data not shown). The low permeability indices $(<0.13 \pm 0.05)$ in neutrophil-depleted rats receiving intradermal injections of neutrophils or anti-BSA alone indicate that reconstituted neutrophils and IgG are required for development of significant vasculitis. Rats that received intradermal neutrophils and IgG, but no intravenous BSA, exhibited permeability indices less than 0.1 (data not shown).

In vivo evidence for neutrophil activation by PAF in the reconstituted dermal vasculitis model. The reconstituted dermal vasculitis model was used to specifically examine the role of PAF receptors on neutrophils in immune complex vasculitis. Neutrophil-depleted rats were reconstituted with varied concentrations (2.5-22 $\mu \mathrm{g})$ of antibody together with neutrophils that had either been pretreated with $50 \mu \mathrm{M} \mathrm{L}-652,731,50$ $\mu \mathrm{M}$ L-652,763, or buffer, and then washed. Vascular injury was consistently decreased nearly $50 \%$ at skin sites in which the neutrophils had been pretreated with the PAF-receptor antagonist, L-652,731 (Fig. 8). Because L-652,763 has been shown to bind rabbit platelet PAF receptors with nearly 1,000-fold less affinity than L-652,731 (50), additional dermal sites were reconstituted with neutrophils incubated in $50 \mu \mathrm{M}$ L-652,763 without subsequent washing. As in the case of the classic reversed passive Arthus reaction, the cis-compound (L-652,763) had no suppressive effect on the evolution of immune complex vasculitis.

To address the possibility that L-652,731 may impede in situ immune complex formation, dermal vasculitis reactions in the presence or absence of L-652,731 $\left(5 \times 10^{-8} \mathrm{~mol}\right)$ were induced in neutrophil-sufficient and depleted rats. These rats received $15 \mu \mathrm{g}\left(10^{6} \mathrm{cpm}\right){ }^{125}$ I-BSA intravenously in lieu of the usual amount of ${ }^{125} \mathrm{I}$-nonspecific IgG $\left(1 \mu \mathrm{g} ; 8 \times 10^{5} \mathrm{cpm}\right)$. This substitution of label allowed comparison of quantity of antigen $\left({ }^{125} \mathrm{I}-\mathrm{BSA}\right)$ concentrated at L-652,731 treated antibody sites as compared to sites injected with antibody in the absence of L-652,731. For both neutrophil-deficient and sufficient rats, there were no differences in radioactive counts between skin plugs obtained from sites injected with L-652,731 or not, suggesting that this antagonist does not impede in situ immune complex formation (data not shown).

Since it has been suggested that formation of hydroxyl radicals $\left(\mathrm{HO}^{\circ}\right)$ may be important in the pathogenesis of neutrophil-mediated tissue injury (56), we examined the effect of L-652,731 on $\mathrm{HO}^{\circ}$ formation by measuring the appearance of thiobarbituric acid reactive products from deoxyribose (55). As shown in Table I, addition of up to $50 \mu \mathrm{M} \mathrm{L-652,731} \mathrm{to} \mathrm{a}$ cell-free $\mathrm{HO}^{\circ}$ generating system (hypoxanthine/xanthine oxidase) resulted in no decrease in detectable $\mathrm{HO}^{\circ}$. Likewise, low concentrations of the vehicle used to solubilize L-652,731 ( $0.1 \%$ DMSO) did not scavenge HO' generated by hypoxanthine/xanthine oxidase.

Time course analysis of PAF-triggered neutrophil activation in immune complex vasculitis. To further characterize the role of PAF-triggered neutrophil activation in the pathogenesis of immune complex vasculitis, we examined the ability of L-652,731 to attenuate reconstituted dermal vasculitis reactions which were allowed to progress for $0.5,1$, or $2 \mathrm{~h}$. As shown in Fig. 9, the maximum development of vascular permeability in the reconstituted dermal vasculitis model occurred by $2 \mathrm{~h}$, in contrast to the reversed passive Arthus reaction where permeability continues to rise for several hours (1, 52). Pretreatment of neutrophils with L-652,731 resulted in suppression of injury at all three time points suggesting that PAF engages neutrophil PAF receptors early in the development of immune complex vasculitis.

Role of neutrophil priming by PAF in immune complex vasculitis. In order to differentiate the effects of priming versus direct activation of neutrophils by PAF, neutrophils were pretreated with either substimulatory (priming) doses of PAF alone, PAF plus L-652,731, PAF plus L-652,763, or buffer alone, then washed and utilized in the reconstituted dermal vasculitis model. At other injection sites neutrophils were incubated with L-652,731 or L-652,763 and then mixed with additional L-652,731 and L-652,763, respectively, before utilization in the reconstituted vasculitis model. As shown in Table II, sites injected with PAF primed neutrophils or neutrophils primed in the presence of the cis-isomer (L-652,763) of receptor antagonist exhibited significantly greater injury than sites injected with buffer-treated neutrophils. Compared to sites injected with buffer-treated cells, there was a nearly $50 \%$ reduction in vascular injury where neutrophils had either been pretreated or coincubated with L-652,731. These data confirm that neutrophils participate in the pathogenesis of immune complex vasculitis through a PAF receptor-linked mechanism and indicate that under these experimental conditions, neutrophil priming by PAF leads to enhanced development of vascular injury in the reconstitution model.

\section{Discussion}

This study indicates that very low concentrations (picomolar to nanomolar) of PAF can "prime" peripheral blood rat neutrophils to produce enhanced quantities of $\mathrm{O}_{2}^{-}$following activation with preformed IgG immune complexes. Higher concentrations of PAF directly activate neutrophils as measured by $\mathrm{O}_{2}^{-}$generation and azurophilic granule release. We have 

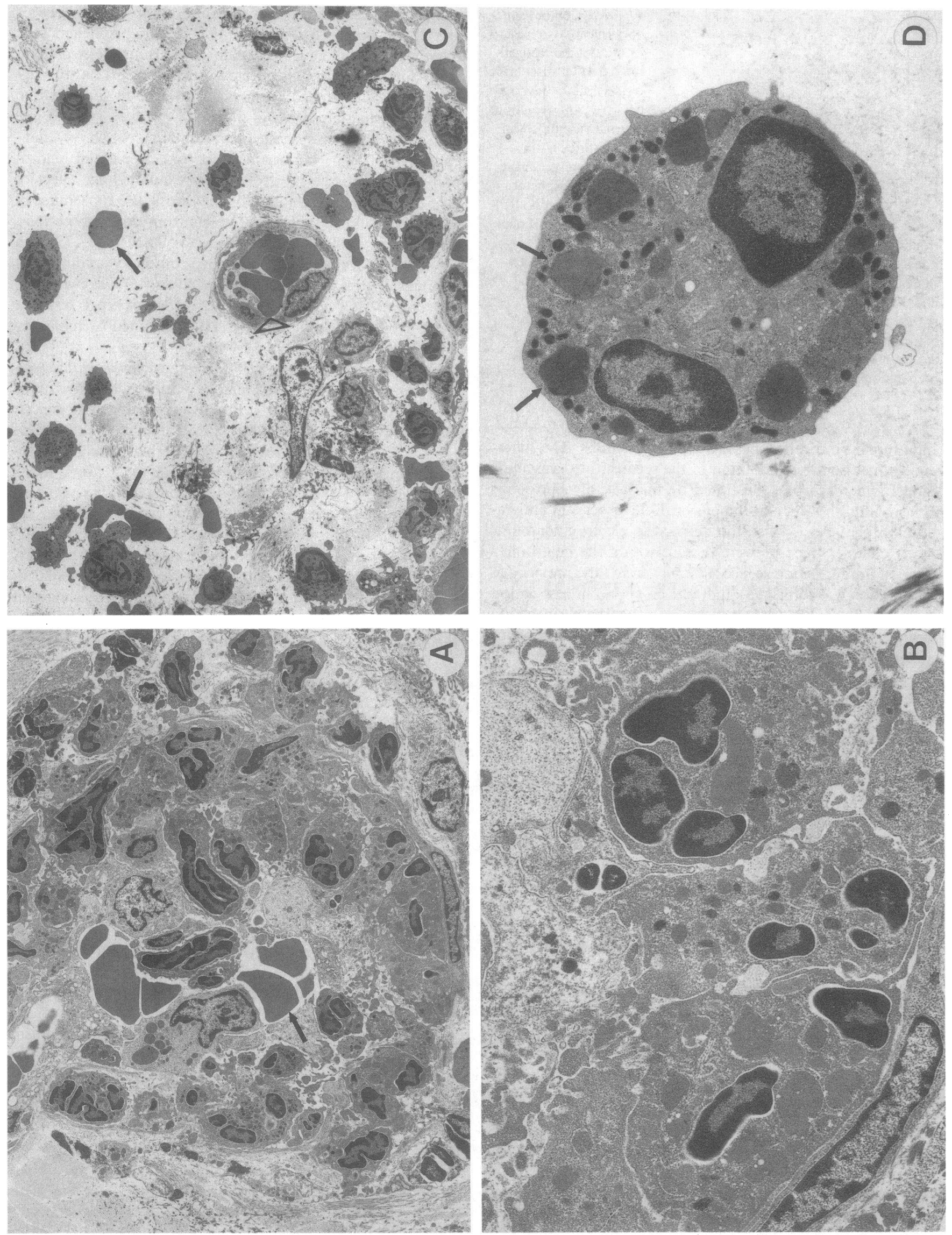


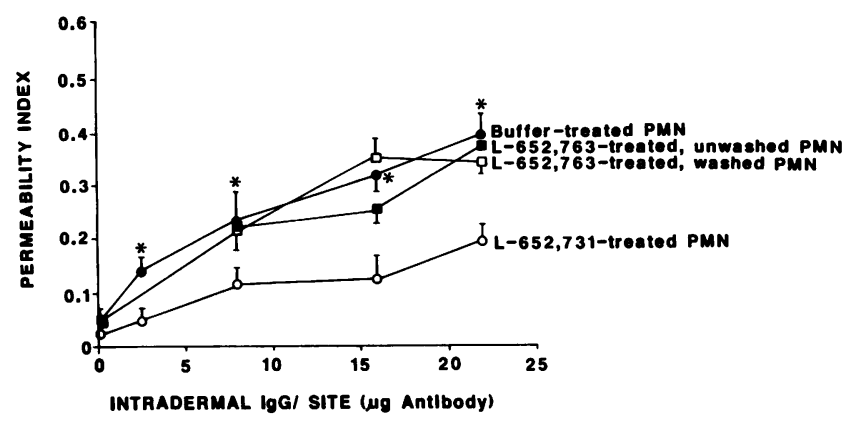

Figure 8. Effect of neutrophil PAF-receptor blockade in development of dermal vasculitis that has been reconstituted in neutrophil-depleted rats. Rats were sacrificed after $2 \mathrm{~h}$ and permeability indices determined as described previously. Sites were reconstituted with buffer-treated washed neutrophils (- - ), neutrophils treated with L-652,731 and washed (-o-), neutrophils treated with L-652,763 and washed ( $-\square-)$, and neutrophils incubated in L-652,763 without subsequent washing (-- - . All intradermal injections included IgG anti-BSA as indicated. The data expressed represent means \pm SEM of two experiments in which four to five replicate sites were employed for each variable. Data were analyzed by two-way analysis of variance for comparison of variables within groups. * A significant difference $(P<0.05)$ between sites reconstituted with buffer-treated neutrophils and sites reconstituted with L-652,731treated cells.

provided evidence that PAF participates in the pathogenesis of immune complex mediated dermal vascular injury through a mechanism triggered through PAF receptors on neutrophils. The potential for augmentation of vascular injury as the result of PAF-triggered neutrophil priming is supported by this study. These observations support the concept that PAF is an important autocrine-paracrine inflammatory mediator and suggest a broader role for PAF than its capacity to provoke rapid, neutrophil-independent increases in vascular permeability (6-11).

The major conclusions from this study are predicated on the specificity and high binding affinity of the recently synthesized PAF receptor antagonist, L-652,731, and the development of the reconstituted dermal vasculitis model. Hwang et al. provided extensive functional and binding analyses that strongly support the conclusion that L-652,731 acts exclusively as a competitive receptor antagonist to PAF (50). In a comparative study, these investigators showed that L-652,731 is a more potent PAF antagonist than CV-3988, kadsurenone, and ginkolide $B$ and that in competitive inhibition analyses of PAF-receptor sites on rabbit platelet membranes it has substantially greater affinity for PAF receptors. Our data indicate that L-652,731 selectively blocks PAF-triggered rat neutrophil activation (as measured by $\mathrm{O}_{2}^{+}$generation and $\beta$-glucuronidase secretion) and corroborate other studies which have shown that this antagonist is specific for the PAF receptor $(12,34,50)$.
Table I. Effect of L-652,731 on Hydroxyl Radical Generation*

\begin{tabular}{lc}
\hline \multicolumn{1}{c}{ Mixture } & $\begin{array}{r}\text { Mean absorbance } \\
( \pm \text { SEM }), 532 \mathrm{~nm}\end{array}$ \\
\hline $\begin{array}{l}\text { Hypoxanthine }(0.58 \mathrm{mM}) \\
\text { Xanthine oxidase }(0.2 \mathrm{U})\end{array}$ & $0.013 \pm 0.03$ \\
Xanthine oxidase/hypoxanthine & $0.032 \pm 0.02$ \\
Xanthine oxidase/hypoxanthine + mannitol & $0.494 \pm 0.10$ \\
$\quad(10 \mathrm{mM})$ & $0.158 \pm 0.08^{\ddagger}$ \\
$\quad$ Xanthine oxidase/hypoxanthine + L-652,731 & \\
$\quad(50 \mu \mathrm{M})$ & $0.450 \pm 0.03^{\S}$ \\
Xanthine oxidase/hypoxanthine + L-652,731 & \\
$\quad(25 \mu \mathrm{M})$ & $0.475 \pm 0.03^{\S}$ \\
Xanthine oxidase/hypoxanthine $+0.1 \%$ & \\
$\quad$ DMSO (L-652,731 vehicle) & $0.482 \pm 0.08^{\S}$ \\
\hline
\end{tabular}

* Hydroxyl radical formation was assayed by formation of a thiobarbituric acid-reactive substance from deoxyribose (55). Mean \pm SEM of three experiments performed in triplicate.

‡ Addition of mannitol (10 mM), a nonspecific HO' scavenger, to xanthine oxidase/hypoxanthine markedly reduced appearance of reactive products; $(P<0.01$; two-way analysis of variance).

${ }^{\S}$ No significant differences compared to values from xanthine oxidase/hypoxanthine above; ( $P>0.1$; two-way analysis of variance).

The reconstituted dermal vasculitis model affords the luxury of ex vivo neutrophil manipulation before introduction into the skin. While this model provides a useful investigative tool, several points should be emphasized. The degree of injury induced in the reconstituted dermal vasculitis model is substantially less than that achieved in the classic reversed dermal Arthus reaction. This is presumably due to the loose distribution of neutrophils around the outsides of vessels, less intimate contact between the neutrophils and vessel wall components, less efficient access to blood-borne mediators, and some loss of neutrophil viability upon introduction into the animal. These attributes of the reconstituted vasculitis are illustrated in Figs. 6 and 7. Despite these caveats, development of vascular injury is dependent on the formation of immune complexes and the presence of viable neutrophils. In the reconstituted dermal vasculitis model, maximum vascular leak occurs earlier than in the reversed passive Arthus reaction (Fig. 9). This may reflect the fact that in the former model, the entire complement of participating neutrophils is injected intradermally at time zero rather than being recruited from the vascular compartment over a period of several hours. It should be emphasized that blockade of neutrophil PAF receptors from the onset does not infer that PAF acts exclusively through neutrophil activation. In the reversed passive Arthus reaction it is likely that the importance of PAF-triggered neutrophil function is related to the concentration of neutrophils present at the site of inflam-

Figure 7. Transmission electron micrographs (TEMs) of reconstituted dermal vasculitis and classic reversed passive Arthus reaction $2 \mathrm{~h}$ after induction of injury. In the reversed passive Arthus reaction $(A)$, neutrophils originating from the vascular space ( $\uparrow)$ have emigrated through the vessel wall and accumulated within the surrounding interstitium. There are numerous large, irregular electron dense immune complex deposits within the neutrophils $(B)$. In the reconstituted vasculitis model $(C)$, the injected neutrophils have distributed within the dermis. Although vascular injury is less pronounced in the reconstitution model than in the reversed Arthus, there is quantitative (Fig. 6) and morphologic evidence of vascular leak. The morphologic evidence consists largely of perivascular edema and the presence of numerous extravascular red blood cells $(\uparrow)$. There are no neutrophils within the vascular lumen $(\Delta)$ or in the process of emigration. Within reconstituted neutrophils $(D)$, there are irregularly shaped electron dense deposits ( $\uparrow$ ) representing ingested immune complexes. TEM magnifications: $A, 2,450 ; B, 1,820 ; C, 7,800 ; D, 13,175$. 


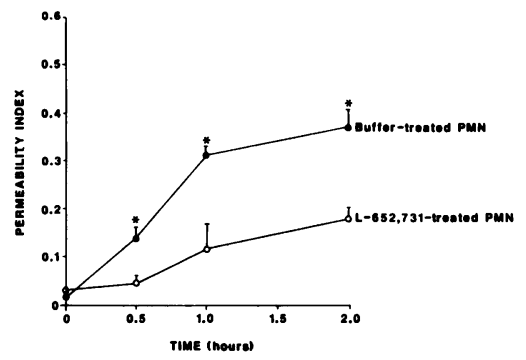
IgG anti-BSA $(20 \mu \mathrm{g})$ as previously described. After $0.5,1$, or $2 \mathrm{~h}$, the rats were sacrificed and permeability indices determined. The data expressed are means \pm SEM of two experiments in which five replicate sites were employed for each variable. A two-tailed Student's $t$ test was used to compare control (๑) versus L-652,731-treated (O) groups. * Significant difference $(P<0.05)$ between control and L-652,731-treated groups.

mation. Clearly, in this model and in pathologic states, there is a graded neutrophil influx into the inflammatory site.

Based on in vivo and in vitro studies in rats, nanomolar concentrations of PAF have been measured in blood, tissue homogenates and peripheral blood neutrophil releasates (57, 58). While the present studies suggest that picomolar and nanomolar concentrations of PAF may be physiologically relevant, it is unclear what concentrations of PAF are elaborated within the milieu of a developing Arthus reaction. Because of such uncertainty, the relative effects of direct neutrophil activation by PAF versus neutrophil priming by PAF are not known. Our in vitro priming experiments are consistent with recently reported work demonstrating the capacity for PAF to

Table II. Role of Neutrophil Priming by PAF in Reconstituted Dermal Vasculitis*

\begin{tabular}{|c|c|c|}
\hline Neutrophil pretreatment & $\begin{array}{l}\text { Permeability index } \\
\quad(\text { Mean } \pm \text { SEM) }\end{array}$ & Percent change $e^{t}$ \\
\hline A Buffer alone, washed & $0.36 \pm 0.03$ & - \\
\hline B PAF $\left(10^{-9} \mathrm{M}\right)$, washed & $0.47 \pm 0.04$ & $\begin{array}{c}\uparrow 31 \% \text { versus } A \\
\text { buffer alone } \\
(P<0.05)\end{array}$ \\
\hline $\begin{array}{l}\text { C PAF }\left(10^{-9} M\right)+L-652,763 \\
(50 \mu M), \text { washed }\end{array}$ & $0.51 \pm 0.06$ & - \\
\hline $\begin{array}{l}\text { D PAF }\left(10^{-9} \mathrm{M}\right)+\mathrm{L}-652,731 \\
(50 \mu \mathrm{M}), \text { washed }\end{array}$ & $0.22 \pm 0.04$ & $\begin{array}{c}\downarrow 50 \% \text { versus } A, \\
\text { buffer alone } \\
\quad(P<0.05)\end{array}$ \\
\hline E No IgG (negative control) & $0.08 \pm 0.06$ & 一 \\
\hline $\begin{array}{c}\text { F L-652,731 }(50 \mu \mathrm{M})+\text { added } \\
\text { L-652,731 }(50 \mu \mathrm{M})\end{array}$ & $0.18 \pm 0.07$ & - \\
\hline $\begin{array}{c}\text { G L-652,763 }(50 \mu \mathrm{M})+\text { added } \\
\text { L-652,763 }(50 \mu \mathrm{M})\end{array}$ & $0.31 \pm 0.04$ & - \\
\hline
\end{tabular}

* Reconstituted dermal vasculitis model carried out as described above: Neutrophil $\left(10^{6}\right)$ preparations were mixed with IgG anti-BSA $(20 \mu \mathrm{g})$ immediately prior to intradermal injection. Permeability indices were determined at $2 \mathrm{~h}$. The data represent the means \pm SEM for three experiments in which six to eight replicate sites were employed per variable.

‡ Data were analyzed by analysis of variance with significant difference assigned for $P<0.05$. prime human neutrophils. Vercellotti et al. (20) have shown that exposure of human neutrophils to substimulatory concentrations of PAF $\left(10^{-12} \mathrm{M}\right)$ followed by stimulation with chemotactic factors or phorbol esters leads to marked enhancement of a variety of proinflammatory neutrophil activities. Such priming also leads to a threefold increase in vitro endothelial cell killing by neutrophils. The in vivo PAF-priming experiments (Table II) conducted in our study revealed a relatively modest increase in vascular injury but nonetheless are supportive of the hypothesis that PAF-primed neutrophils can amplify tissue injury. A possible explanation for the less marked in vivo priming effect seen in our study hinges on the observation neutrophils damage blood vessels "from without" in the reconstitution model. One result of this model characteristic would be the lessened importance of direct neutrophilendothelial cell adhesive interactions. Among the effects of PAF-triggered neutrophil priming reported by Vercellotti et al. was increased granulocyte adhesion and surface adhesogen (CR3) expression (20). It is likely that the diminution of specific endothelial cell-neutrophil adhesive interactions would lessen the enhancement of vascular injury that can be achieved by PAF-primed neutrophils. Clearly, the in vivo system is complex and other factors doubtlessly influence the magnitude of vascular leak that occurs in immune complex vasculitis. The present study supports the premise that both direct neutrophil activation and neutrophil priming by PAF could potentially be operative in the pathogenesis of immune complex vasculitis. It is possible that the predominant PAF-induced effects on neutrophil function in evolving tissue injury vary depending on the local concentration of PAF and the stage at which the response is examined.

In evolving immune complex vasculitis the cellular sources of endogenous PAF are unknown. Kravis and Henson (59) demonstrated an early phase of neutrophil and complementindependent edema formation and platelet accumulation at skin sites in reversed passive Arthus reactions in rabbits. They suggested that PAF released from tissue mast cells by an IgEdependent mechanism may be responsible. PAF is also produced by neutrophils, endothelial cells, and platelets (5). Hellewell and Williams (12) have suggested that PAF is formed in close proximity to microvascular endothelial cells during development of an Arthus reaction and that neutrophils undergoing phagocytosis of immune complexes may be the major source of PAF. The extent to which platelets or endothelial cells may contribute PAF is unclear.

Although there is convincing evidence that exogenous PAF can induce neutrophil-independent increases in vascular permeability (6-11) and that PAF exhibits stimulatory properties with respect to neutrophils (13-19), the relationship between neutrophils and endogenous PAF in the context of immune complex vasculitis has been unclear. Hellewell and Williams (12) have suggested that L-652,731 inhibits the Arthus reaction by blocking the effects of endogenous PAF. These investigators showed that L-652,731 does not inhibit kinin generation, C5a generation, lipoxygenase activity, or cyclooxygenase activity. Our observations that L-652,731 does not impede immune complex formation or scavenge $\mathrm{HO}^{\circ}$ lend further indirect support to this conclusion. The present study does not address the products that are derived from activated neutrophils and responsible for tissue injury. There is evidence suggesting roles for diverse neutrophil products, including proteases, oxidants, arachidonate metabolites, and cationic 
proteins/peptides in immune complex-induced tissue injury (1-4).

These data indicate that PAF participates in the pathogenesis of immune complex vasculitis through a neutrophil PAFreceptor mediated mechanism. In vitro data suggest that peripheral blood rat neutrophils may be directly activated or primed by picomolar to nanomolar concentrations of PAF to produce enhanced quantities of proinflammatory mediators. PAF appears to participate in the pathogenesis of immune complex vasculitis through both neutrophil-independent and neutrophil-dependent mechanisms.

\section{Acknowledgments}

We thank Dr. John C. Chabala of the Merck Sharp and Dohme Research Laboratories for providing L-652,731 and L-652,763. We are grateful to Robin G. Kunkel and Kimberly D. Drake for skillful preparations of the figures and manuscript, respectively.

This work was supported in part by National Institutes of Health grants HL-34635, HL-31963, GM-29507, and HL-28442.

\section{References}

1. Cochrane, C. G., and B. S. Aikin. 1966. Polymorphonuclear leukocytes in immunologic reactions. The destruction of vascular basement membrane in vivo and in vitro. J. Exp. Med. 124:733-742.

2. Henson, P. M., and R. B. Johnston, Jr. 1987. Tissue injury in inflammation. Oxidants, proteinases, and cationic proteins. J. Clin. Invest. 79:669-674.

3. Johnston, R. B., Jr., and J. F. Lehmeyer. 1976. Elaboration of toxic oxygen by-products by neutrophils in a model of immune complex disease. J. Clin. Invest. 57:836-841.

4. Fantone, J. C., and P. A. Ward. 1982. Role of oxygen-derived free radicals and metabolites in leukocyte-dependent inflammatory reactions. Am. J. Pathol. 107:397-418.

5. Benveniste, J., and B. Arnoux. 1983. Platelet Activating Factor and Structurally Related Ether-Lipids. Elsevier Scientific Publishing Co., Amsterdam, The Netherlands.

6. Wedmore, C. V., and T. J. Williams. 1981. Platelet-activating factor (PAF), a secretory product of polymorphonuclear leukocytes, increases vascular permeability in rabbit skin. Br. J. Pharmacol. 74:916P.

7. Humphrey, D. M., L. M. McManus, K. Satouchi, D. J. Hanahan, and R. N. Pinckard. 1982. Vasoactive properties of acetyl glyceryl ether phosphorylcholine and analogues. Lab. Invest. 46:422-427.

8. Morley, J., C. P. Page, and W. Paul. 1983. Inflammatory actions of platelet-activating factor (Paf-acether) in guinea-pig skin. $\mathrm{Br} . J$. Pharmacol. 80:303-308.

9. Archer, C. B., C. P. Page, W. Paul, J. Morley, and D. M. MacDonald. 1984. Inflammatory characteristics of platelet-activating factor (Paf-acether) in human skin. Br. J. Dermatol. 110:45-51.

10. Pirotzky, E., C. P. Page, R. Roubin, A. Pfister, W. Paul, J. Bonnet, and J. Benveniste. 1984. Paf-acether induced plasma exudation in rat skin is independent of platelets and neutrophils. Microcirc. Endothel. Lymphatics. 1:107-112.

11. Wedmore, C. V., and T. J. Williams. 1981. Control of vascular permeability by polymorphonuclear leukocytes in inflammation. $\mathrm{Na}$ ture (Lond.). 289:646-648.

12. Hellewell, P. G., and T. J. Williams. 1986. A specific antagonist of platelet-activating factor suppresses oedema formation in an Arthus reaction but not oedema induced by leukocyte chemoattractants in rabbit skin. J. Immunol. 137:302-307.

13. Shaw, J. O., R. N. Pinckard, S. Ferrigni, L. M. McManus, and D. J. Hanahan. 1981. Activating of human neutrophils with 1-0-hexadecyl/octadecyl-2-acetyl-sn-glyceryl-3-phosphorylcholine (platelet activating factor). J. Immunol. 127:1250-1255.
14. O'Flaherty, J. T., R. L. Wykle, C. J. Lees, T. Shewmake, C. E. McCall, and M. J. Thomas. 1981. Neutrophil-degranulating action of 5,12-dihydroxy-6,8,10,14-eicosatetraenoic acid and 1-0-alkyl-2-0-acetyl-sn-glycero-3-phosphocholine. Am. J. Pathol. 105:264-269.

15. Englberger, W., D. Bitter-Suermann, and U. Hadding. 1987. Influence of lysophospholipids and PAF on the oxidative burst of PMNL. Int. J. Immunopharmacol. 9:275-282.

16. Ingraham, L. M., T. D. Coates, J. M. Allen, C. P. Higgins, R. L. Baehner, and L. A. Boxer. 1982. Metabolic, membrane, and functional responses of human polymorphonuclear leukocytes to platelet-activating factor. Blood. 59:1259-1271.

17. Gay, J., J. K. Beckman, K. A. Zaboy, and J. N. Lukens. 1986. Modulation of neutrophil oxidative responses to soluble stimuli by platelet-activating factor. Blood. 67:931-938.

18. Ingraham, L., J. E. Lafuze, L. A. Boxer, and R. L. Baehner. 1987. In vitro and in vivo effects of treatment by platelet activating factor on n-formyl-met-leu-phe-mediated responses of polymorphonuclear leukocytes. Br. J. Haematol. 66:219-228.

19. Wickham, N. W. R., G. M. Vercellotti, H. Q. Yin, C. F. Moldow, and H. S. Jacob. 1987. Neutrophils are primed to release toxic oxidants by contact with thrombin-stimulated endothelium:role of endothelial cell-generated platelet activating factor. Clin. Res. 603a. (Abstr.)

20. Vercellotti, G. M., H. Q. Yin, K. S. Gustafson, R. D. Nelson, and H. S. Jacob. 1988. Platelet-activating factor primes neutrophil responses to agonists: Role in promoting neutrophil-mediated endothelial damage. Blood. 71:1100-1107.

21. Mencia-Huerta, J. M., R. A. Lewis, E. Razin, and K. F. Austen. 1983. Antigen-initiated release of platelet-activating factor (PAFacether) from mouse bone marrow-derived mast cells sensitized with monoclonal IgE. J. Immunol. 131:2958-2964.

22. Camussi, G., C. Tetta, R. Coda, and J. Benveniste. 1981. Release of platelet-activating factor in human pathology. I. Evidence for the occurrence of basophil degranulation and release of platelet-activating factor in systemic lupus erythematosus. Lab. Invest. 44:241248.

23. Buxton, D. B., D. J. Hanahan, and M. S. Olson. 1984. Stimulation of glycogenolysis and platelet-activating factor production by heat-aggregated immunoglobulin $\mathrm{G}$ in the perfused rat liver. J. Biol. Chem. 259:13758-13763.

24. Mencia-Huerta, J. M., and J. Benveniste. 1981. Platelet-activating factor (PAF-acether) and macrophages. II. Phagocytosis-associated release of PAF-acether from rat peritoneal macrophages. Cell. Immunol. 57:281-289.

25. Camussi, G., F. Bussolino, C. Tetta, F. Caligaris Cappio, R. Coda, E. Macchiorlatti, M. Alberton, C. Roffinello, and G. Segoloni. 1983. Effect of prostacyclin $\left(\mathrm{PGI}_{2}\right)$ on immune-complex-induced neutropenia. Immunology 48:625-632.

26. Camussi, G., C. Tetta, F. Bussolino, F. Caligaris Cappio, R. Coda, C. Masera, and G. Segoloni. 1981. Mediators of immune-complex-induced aggregation of polymorphonuclear neutrophils. II. Platelet-activating factor as the effector substance of immune-induced aggregation. Int. Arch. Allergy Appl. Immunol. 64:25-35.

27. Sanchez-Crespo, M., F. Alonso, and J. Egido. 1980. Plateletactivating factor in anaphylaxis and phagocytosis. I. Release from human peripheral polymorphonuclears and monocytes during the stimulation by ionophore A23187 and phagocytosis but not from degranulating basophils. Immunology. 40:645-652.

28. Virella, G., M. F. L. Lopes-Virella, C. Shuler, T. Sherwood, G. A. Espinoza, P. Winocour, and J. A. Colwell. 1983. Release of PAF by human polymorphonuclear leukocytes stimulated by immune complexes bound to Sepharose particles and human erythrocytes. Immunology. 50:43-50.

29. Camussi, G., C. Tetta, M. Deregibus, F. Bussolino, G. Segoloni, and A. Vercellone. 1982. Platelet-activating factor (PAF) in experimentally induced rabbit acute serum sickness: role of basophil-derived PAF in immune complex deposition. J. Immunol. 128:86-95.

30. Pinckard, R. N., L. M. McManus, and D. J. Hanahan. 1982. 
Chemistry and biology of acetylglyceryl ether phosphorylcholine (platelet activating factor). In Advances in Inflammation Research. Vol. 4. G. Weissmann, editor. Raven Press, New York. 147-160.

31. Camussi, G., I. Paulowski, F. Bussolino, P. R. B. Caldwell, J. Brentjens, and G. Andres. 1983. Release of platelet-activating factor in rabbits and antibody mediated injury of the lung: the role of leukocytes and of pulmonary endothelial cells. J. Immunol. 131:1802-1811.

32. Pinckard, R. N., R. S. Farr, and D. J. Hanahan. 1979. Physicochemical and functional identity of rabbit platelet-activating factor (PAF) released in vivo during IgE anaphylaxis with PAF released in vitro from IgE sensitized basophils. J. Immunol. 123:1847-1853.

33. Inarrea, P., F. Alonso, and M. Sanchez-Crespo. 1983. Plateletactivating factor: an effector substance of the vasopermeability changes induced by the infusion of immune aggregates in the mouse. Immunopharmacology. 6:7-16.

34. Doebber, T. W., Wu, M. S., and T. Biftu. 1986.'Platelet-activating factor (PAF) mediation of rat anaphylactic responses to soluble immune complexes. Studies with PAF receptor antagonist L-652,731. J. Immunol. 136:4659-4668.

35. Camussi, G., C. Tetta, G. Segoloni, M. C. Deregibus, and F. Bussolino. 1981. Neutropenia induced by platelet-activating factor (PAF-acether) released from neutrophils: the inhibitory effect of prostacyclin. Agents Actions. 11:550-558.

36. Doebber, T. W., M. S. Wu, and T. Y. Chen. 1984. Platelet activating factor intravenous infusion in rats stimulates vascular lysosomal hydrolase secretion independent of blood neutrophils. Biochem. Biophys. Res. Commun. 125:980-987.

37. Sanchez-Crespo, M., F. Alonso, P. Inarrea, V. Alvarez, and J. Egido. 1982. Vascular actions of PAF-acether (a synthetic platelet-activating factor) in the rat: evidence for a platelet independent mechanism. Immunopharmacology. 4:173-180.

38. Blank, M. L., F. Snyder, W. Beyers, B. Brooks, and E. E. Muirhead. 1979. Antihypertensive activity of alkyl ether analog of phosphatidylcholine. Biochem. Biophys. Res. Commun. 90:11941199.

39. Handley, D. A., C. M. Arbeeny, M. L. Lee, R. G. VanValen, and R. N. Saunders. 1984. Effect of platelet activating factor on endothelial permeability to plasma macromolecules. Immunopharmacology. 8:137-143.

40. Humphrey, D. M., L. McManus, D. J. Hanahan, and R. N. Pinckard. 1984. Morphologic basis of increased vascular permeability induced by acetyl glyceryl ether phosphorylcholine. Lab. Invest. 50:16-24.

41. Bussolino, F., M. Aglietta, F. Sanavio, A. Stacchini, D. Lauri, and G. Camussi. 1985. Alkcyl-ether phosphoglycerides influence calcium influxes into human endothelial cells. J. Immunol. 135:27482755.

42. Brock, T. A., and M. A. Gimbrone, Jr. 1986. Platelet activating factor alters calcium homeostasis in cultured vascular endothelial cells. Am. J. Physiol. 250:H1086.

43. Bussolino, F., G. Camussi, M. Aglietta, P. Braquet, A. Bosia, G. Pescarmona, F. Sanavio, N. D'Urso, and P. C. Marchisio. 1987. Human endothelial cells are target for platelet-activating factor. I. Platelet-activating factor induces changes in cytoskeleton structures. $J$. Immunol. 139:2439-2446.
44. Lynch, J. M., G. Z. Lotner, S. J. Betz, and P. M. Henson. 1979. The release of a platelet-activating factor by stimulated rabbit neutrophils. J. Immunol. 123:1219-1226.

45. Henson, P. M. 1976. Activation and desensitization of platelets by platelet-activating factor (PAF) derived from IgE-sensitized basophils. I. Characteristics of the secretory response. J. Exp. Med. 143:937-946.

46. Henry, R. J., N. Chiamori, O. J. Golub, and S. Berkman. 1960. Revised spectrophotometric methods for the determination of glutamic-oxalacetic transaminase, glutamic-pyruvic transaminase, and latic acid dehydrogenase. Am. J. Clin. Pathol. 34:381-398.

47. Wadsworth, A., F. Maltaner, and E. Maltaner. 1931. The quantitative determination of the fixation of complement by immune serum and antigen. J. Immunol. 21:313-319.

48. Babior, B. M., R. S. Kipnes, and J. T. Curnutte. 1973. Biological defense mechanism: The production by leukocytes of superoxide, a potential bactericidal agent. J. Clin. Invest. 52:741-744.

49. Weissman, G., H. M. Korchak, H. D. Perez, J. E. Smolen, I. M. Goldstein, and S. Hoffstein. 1978. Leukocytes as secretory organs in inflammation. In Advances in Inflammation Research. G. Weissmann, B. Samuelsson, and R. Paoletti, editors. Raven Press, New York. 95-112.

50. Hwang, S. B., M. H. Lam, T. Biftu, T. R. Beattie, and T. Y. Shen. 1985. Trans-2,5-bis-(3,4,5-trimethoxyphenyl) tetrahydrofuran. An orally active specific and competitive receptor antagonist of platelet activating factor. J. Biol. Chem. 260:15639-15645.

51. Johnson, K. J., and P. A. Ward. 1974. Acute immunologic pulmonary alveolitis. J. Clin. Invest. 54:349-357.

52. Ward, P. A., and C. G. Cochrane. 1965. Bound complement and immunologic injury of blood vessels. J. Exp. Med. 121:215-233.

53. McCormick, J. R., M. M. Harkin, K. J. Johnson, and P. A. Ward. 1981. Suppression of superoxide dismutase of immune complex-induced pulmonary alveolitis and dermal inflammation. Am. J. Pathol. 102:55-61.

54. McCord, J. M., and E. D. Day, Jr. 1978. Superoxide dependent production of hydroxyl radical catalyzed by iron-EDTA complex. FEBS (Fed. Eur. Biochem. Soc.) Lett. 86:139-146.

55. Halliwell, B., and J. M. C. Gutteridge. 1981. Formation of a thiobarbituric-acid-reactive substance from deoxyribose in the presence of iron salts. FEBS (Fed. Eur. Biochem. Soc.) Lett. 128:347-354.

56. Ward, P. A., G. O. Till, R. Kunkel, and C. Beauchamp. 1983. Evidence for a role of hydroxyl radical in complement and neutrophil-dependent tissue injury. J. Clin. Invest. 72:789-801.

57. Chang, S. W., C. O. Feddersen, P. M. Henson, and N. F. Voelkel. 1987. Platelet-activating factor mediates hemodynamic changes and lung injury in endotoxin-treated rats. J. Clin. Invest. 79:1498-1509.

58. Ramesha, C. S., and W. C. Pickett. 1986. Platelet-activating factor and leukotriene biosynthesis is inhibited in polymorphonuclear leukocytes depleted of arachidonic acid. J. Biol. Chem. 261:75927595.

59. Kravis, T. C., and P. M. Henson. 1977. Accumulation of platelets at sites of antigen-antibody-mediated injury: a possible role for $\mathrm{IgE}$ antibody and mast cells. J. Immunol. 118:1569-1576. 